\title{
An Assessment of the Anti-Inflammatory, Antimicrobial, and Antioxidant Activities of Ficus sur Stem-Bark
}

\author{
Clement Osei Akoto*, Akwasi Acheampong, Osei Kwame and Bartholomew Aning Boateng \\ Department of Chemistry, Kwame Nkrumah University of Science and Technology (KNUST), Ghana
}

Submission: May 13, 2020; Published: May 27, 2020

"Corresponding author: Clement Osei Akoto, Department of Chemistry, Faculty of Physical and Computational Sciences, College of Science, Kwame Nkrumah University of Science and Technology (KNUST), Ghana

\begin{abstract}
Ficus sur (Moraceae), is a plant that has found use in traditional African medicine in the treatment of sickle cell disease, epilepsy, pain and inflammations. The present study was aimed at investigating hexane and methanol stem-bark extracts of Ficus sur for their phytoconstituents, anti-inflammatory, antimicrobial and antioxidant activities. Phytochemical screenings were performed using standard protocols. In-vitro antiinflammatory activities were assessed using egg albumin denaturation method. In-vitro antimicrobial (agar and broth dilution method) and antioxidant [total antioxidant capacity (TAC), DPPH and $\mathrm{H}_{2} \mathrm{O}_{2}$ scavenging] assays were carried out on the extracts. Thin layer chromatography was employed in the separation of the components of both extracts. The phytochemical investigation revealed the presence of secondary metabolites such as anthraquinones, terpenoids, flavonoids, steroids, saponins, phenols and tannins. The extracts showed anti-inflammatory activity comparable to that of diclofenac sodium. The extracts showed antimicrobial activity against test organisms with MICs ranging from $2.5-40 \mathrm{mg} /$ $\mathrm{mL}$. The $\mathrm{IC}_{50}$ values for methanol and hexane extracts in the DPPH and $\mathrm{H}_{2} \mathrm{O}_{2}$ assays were $89.95 \pm 0.30$ and $350.70 \pm 0.72 \mu \mathrm{g} / \mathrm{mL}$ and $708.51 \pm$ 0.28 and $682.76 \pm 0.20 \mu \mathrm{g} / \mathrm{mL}$, respectively. The TAC (gAAE/ $100 \mathrm{~g}$ ) for methanol and hexane extracts were $23.560 \pm 0.014$ and $17.863 \pm 0.037 \mathrm{~g}$, respectively. The results suggest that the stem bark of Ficus sur could be exploited as potential therapeutic candidate for the treatment of bacterial infections, inflammations and diseases associated with oxidative-stress.
\end{abstract}

Keywords: Ficus sur; Antimicrobial; Antioxidant; Anti-Inflammatory; Phytochemical

\section{Introduction}

Medicinal plants are known to have antioxidant, antimicrobial, anthelminthic, anti-inflammatory and wound healing activities amongst others [1-3]. They are classified as the richest bio-resource, because they are the source of modern medicines, nutraceuticals, functional foods, food supplements, folk medicines, pharmaceutical intermediates and chemical entities for synthetic drugs [4]. Without specific knowledge of their cellular actions or mechanisms, various parts of plants have been used in traditional medicine to treat a variety of diseases and even as poisons (phytotoxins) [5].

Ficus is a genus of woody plants that comprises about 850 plant species and belongs to the family Moraceae. They are collectively called Figure trees or Figures and are distributed throughout the tropics and temperate zones, including most African countries such as Ghana, Burkina Faso, Nigeria and Cameroon. Ficus sur, a medicinal species of the family Moraceae has many therapeutic applications. A powdered preparation of the bark has been used to treat skin rashes and mouth sores in most parts of Africa.
A leaf preparation by maceration is used to cure chest problems. A decoction of the leaf has been used as a disinfectant wash and as a cure to ophthalmia [6]. Studies have shown antispasmodic and antiplasmodial activities from aqueous extracts of bark and leaves [7].

Other parts of $F$ sur have proven to be potent against a wide variety of ailments including gonorrhoea, sore throat, toothache, eye problems and many more [8]. F. sur is used in folk medicine for the treatment of sickle cell disease in Burkina Faso [9]. Traditional medicine practitioners in Nigeria use $F$. sur for effective management of epilepsy [10]. F. sur is used in the treatment of leprosy, infertility, gonorrhea, rickets, circumcision, oedema, respiratory disorders and many more [11]. Both root and bark decoctions of F. sur are recorded to have caused death, due to toxic substances [12]. The application of this plant species in the treatment of microbial diseases (example gonorrhoea), and in the treatment of sickle cell disease and management of epilepsy portrays it (Ficus sur) as a candidate for research. 
Most research studies conducted on the pharmacological potential of Ficus sur were mainly focused on crude extracts of the leaves, roots, barks [12,13] and fruits [14]. Nevertheless, it is also important to identify the bioactive compounds responsible for each one of the ascribed bioactivities, especially for the stem-bark. At the time of carrying out this research, next to nothing had been reported on the anti-inflammatory activities of the stem-bark. The aim of this study was to examine the efficacy of Ficus sur methanol and hexane extracts as an anti-inflammatory, antimicrobial and antioxidant using in vitro assays.

\section{Materials and Methods}

\section{Sample collection and identification}

The stem-barks of Ficus sur were collected in the month of October, 2018 at Kwahu-Asakraka, (Latitude: 6³7'44" N and Longitude: $0^{\circ} 41^{\prime} 29^{\prime \prime} \mathrm{W}$ ) in the Eastern Region of Ghana with the help of a local herbalist. They were taxonomically identified and authenticated by Mr. Clifford Asare at the Department of Herbal Medicine, Faculty of Pharmacy and Pharmaceutical Sciences, KNUST, Kumasi, Ghana. A voucher specimen number (KNUST/HMI/2019/ S042) was deposited in the Herbarium of Faculty of Pharmacy and Pharmaceutical Sciences for reference purposes.

\section{Chemicals and reagents}

All chemicals were purchased from Sigma Aldrich Co. Ltd, Irvine, U.K., except the standard drugs. The organic solvents were of analytical grade and procured from BDH Laboratory Supplies (England).

\section{Extraction of plant material}

The stem-barks of Ficus sur were thoroughly washed, first under running water to remove any form of debris and subsequently rinsed in distilled water to exclude dissolve heavy metals in tap water $[1,2]$. The stem-barks were chopped into smaller pieces, air dried under shade for two weeks, pulverized into coarse powder, and stored in a desiccator until analysis.

\section{Preparation of methanol and hexane extracts}

Maceration was used for the extraction of the phytoconstituents of the pulverized sample. A mass of $100 \mathrm{~g}$ of the pulverized sample of $F$. sur was soaked separately in $500 \mathrm{~mL}$ of methanol and hexane and macerated with gentle stirring for 72 hours at ambient temperature. The methanol and hexane extracts were condensed and evaporated to dryness using the rotary evaporator at $50{ }^{\circ} \mathrm{C}$ (BUCHI Rota vapor R-114). The extracts were dried and the percentage yield of extracts with respect to powdered plant material determined. The extracts were then stored at $4{ }^{\circ} \mathrm{C}$ in a refrigerator.

\section{Phytochemical screening of extracts}

The pulverized sample and the crude extracts obtained were screened to assess the presence of phytoconstituents using the methods described by Trease and Evans (2009) [15].

\section{In-vitro anti-inflammatory assay using egg albumin de- naturation}

Anti-inflammatory assay was carried out according to a modification of the standard methods by Kumari [16]. Stock solutions of $1000 \mu \mathrm{g} / \mathrm{mL}$ of both extracts were prepared by using sterile distilled water as a solvent. From the stock solutions, various concentrations of $800,600,200$ and $100 \mu \mathrm{g} / \mathrm{mL}$ were prepared using sterile distilled water as a solvent.

The reaction mixtures of total volume $5 \mathrm{~mL}$ were prepared by dissolving $0.2 \mathrm{~mL}$ of egg albumin (fresh egg of a hen), $2.8 \mathrm{~mL}$ of phosphate buffer saline (PBS, $\mathrm{pH}$ of 6.4) and $2 \mathrm{~mL}$ of the various concentrations of extract solutions. A volume of $2 \mathrm{~mL}$ of 200 $\mu \mathrm{g} / \mathrm{mL}$ of diclofenac sodium was used as the standard reference drug and $2 \mathrm{~mL}$ of double distilled water solution served as negative control. The mixtures were incubated at $37{ }^{\circ} \mathrm{C}$ in Bio-Oxygen Demand (BOD) incubator for 15 minutes.

The mixtures were then heated in a water bath at $70{ }^{\circ} \mathrm{C}$ for 5 minutes to induce denaturation. The absorbance of the solutions was measured in triplicate at $660 \mathrm{~nm}$ using UV-vis spectrophotometer. The procedure was independently repeated to obtain three independent sets of data for the analysis in triplicate. The percentage inhibition of protein denaturation was calculated as follows:

$$
\% \text { Inhibition }=\frac{A_{0}-A}{A_{0}} \times 100 \%
$$

Where, $A_{0}=$ absorbance of negative control; $A=$ absorbance of test solution

\section{Antimicrobial activity}

Agar well diffusion and Broth micro-dilution (minimum inhibitory concentration) assays were employed to assess the antimicrobial activities of the extracts.

\section{Sources of microorganisms}

Four bacteria and one fungus were used as test organisms. There were two Gram positive bacteria (Staphylococcus aureus and Enterococcus faecalis) and two Gram negative bacteria (Escherichia coli, Pseudomonas aeruginosa). The fungus was Candida albicans. The microbial strains were provided by the Pharmaceutical Microbiology Section of the Department of Pharmaceutics, Faculty of Pharmacy and Pharmaceutical Science, KNUST, Kumasi. The microbial strains were sub-cultured on nutrient agar slants and incubated at $37^{\circ} \mathrm{C}$ for 24 hours.

\section{Inoculum preparation}

Bacterial isolates were streaked onto nutrient agar (Oxoid, United Kingdom) plates and incubated for $18-24$ hours at $37^{\circ} \mathrm{C}$. Using the direct colony suspension method, suspensions of the organisms were made in nutrient broth and incubated overnight at $37^{\circ} \mathrm{C}$. For the tests, colony suspensions in sterile saline was adjusted to $0.5 \mathrm{McF}$ arland standard and further diluted in sterile double strength nutrient broth $\left(\sim 2 \times 10^{5} \mathrm{CFU} / \mathrm{mL}\right)$ [17]. 


\section{Agar well diffusion}

The antimicrobial activities of the different extracts were determined using a modification of the agar well diffusion standard method previously described $[1,18]$. Ciprofloxacin $(0.05 \mathrm{mg} / \mathrm{mL})$ and clotrimazole $(0.05 \mathrm{mg} / \mathrm{mL})$ were used as the standard reference antimicrobial drug. The extracts and antibiotics were tested in triplicates and mean zones of inhibition were calculated for each extract and the standard antibiotic.

\section{Broth micro-dilution}

In the determination of the minimum inhibitory concentration (MIC), the method used was a modification of micro-well dilution standard method previously described $[1,18]$. Ciprofloxacin and clotrimazole were used as positive control. The experiment was carried out in triplicate.

\section{In vitro antioxidant assays}

Three main assays were employed for the antioxidant activity determination. They were the 1,1-diphenyl-2-picryl-hydrazyl (DPPH) free radicals scavenging, Hydrogen Peroxide scavenging $\left(\mathrm{H}_{2} \mathrm{O}_{2}\right)$ and the Total Antioxidant Capacity (TAC) assays.

\section{DPPH radical scavenging assay}

The DPPH free radical scavenging activity of the two extracts were examined using the standard methods previously described $[1,19]$. Ascorbic acid was used as reference standard. The experiment was independently repeated to obtain three independent sets of data for the analysis. The absorbance was measured at 517 $\mathrm{nm}$. DPPH radical scavenging (\%) was calculated using the formula:

$$
\% \text { Scavenging }=\frac{A_{0}-A}{A_{0}} \times 100 \%
$$

Where, $A_{0}=$ absorbance of control; $A=$ absorbance of test solution

\section{Hydrogen peroxide scavenging assay}

Determination of hydrogen peroxide scavenging potential of the extracts were carried out employing the standard methods previously described [1, 20]. Gallic acid was used as reference standard. Absorbance was taken at $510 \mathrm{~nm}$ using a UV-vis spectrophotometer. The experiment was independently repeated to obtain three independent sets of data for the analysis. The percentage scavenging activity was calculated using the formula below

$$
\% \text { Scavenging }=\frac{A_{\text {test }}-A}{A_{\text {control }}} \times 100 \%
$$

Where $\mathrm{A}_{\text {test }}$ is absorbance of the test samples and $\mathrm{A}_{\text {control }}$ is the absorbance of the negative control. The results were further reported in $\mathrm{IC}_{50}$

\section{Total antioxidant capacity (TAC) assay}

A methodology previously described was used to study the total antioxidant capacity of the extracts of $F$. sur $[1,21]$. Ascorbic acid was used as the reference standard antioxidant and distilled water was used as the blank. The absorbance of the solutions was measured in triplicates using a UV-visible spectrophotometer at $695 \mathrm{~nm}$. The experiment was independently repeated to obtain three independent sets of data for the analysis. From the linear equation of the ascorbic acid concentration-absorbance plot, the corresponding independent variables as ascorbic acid equivalents (AAE) were determined, and the results expressed as gAAE/100g ascorbic acid.

\section{Thin layer chromatography (TLC)}

The number of components present in the extracts were determined by the analytical TLC method. The pre-coated silica gel plates $(0.25 \mathrm{~mm})$ with a fluorescent indicator (F254) were spotted with the extracts about $1 \mathrm{~cm}$ from the bottom edge of plates, with the aid of capillary tubes and allowed to dry [1,22]. Various Solvent systems of petroleum ether/ethyl acetate and hexane/ ethyl acetate in the ratio of 9:1 and 8:2 respectively were used. The ratio of 8:2 (hexane/ethyl acetate) gave the best separation of components for all the extracts. The plates were dried and visualized by a $254 \mathrm{~nm}$ UV lamp. The separated spots were then marked and their sample and solvent fronts were measured.

The retardation factor $\left(\mathrm{R}_{\mathrm{f}}\right)$ of the eluted spots was calculated as follows:

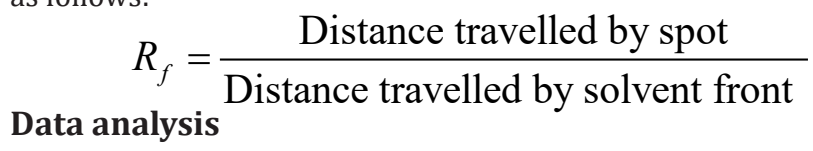

Microsoft Excel 2016 and GraphPad Prism 6.0 for Windows (GraphPad Sofware, San Diego, CA, USA) were used for all data analyses and graphs.

\section{Results and Discussion}

\section{Extraction of plant material}

The yields of the extract in relation to the powdered plant material were calculated as percentages. The yields were 2.71 and $1.62 \%$ for methanol and hexane extracts respectively.

\section{Phytochemical screening}

The therapeutic activities of plants are as a result of the presence of complex chemical constituents in different parts [23]. The phytochemical screening revealed the presence of seven secondary metabolites out of the nine tested for in the pulverized sample and the methanol extract, with alkaloids and carotenoids being absent. Alkaloids, carotenoids and phenols were absent in the hexane extract (Table 1).

The methanol and hexane extracts had six phytochemicals in common, that is anthraquinones flavonoids, saponins, steroids, tannins and terpenoids. The absence of alkaloids in the stem-bark of $F$. sur corroborates the work of Adebayo [24] who investigated haematinic properties of methanolic stem-bark and fruit extracts of Ficus sur in rats pre-exposed to phenylhydrazine induced haemolytic anaemia [24]. Secondary metabolites of plants which include phenolics and flavonoids, have been shown to exhibit 
several biological activities such as antioxidant, antiaging, antidiabetic, antimutagenic, anticarcinogenic, anti-inflammatory and antimicrobial [25]. Saponins have a wide range of pharmacological properties, including antifungal, antiparasitic, molluscicidal and anti-inflammatory [26]. The presence of these phytochemicals in the extracts of $F$. sur stem-bark indicate that they will play a key role in the prevention of various bacterial infections, inflammations and diseases associated with oxidative-stress.

Table 1: Phytochemical constituents of the pulverized sample and the extracts of $F$. sur.

\begin{tabular}{|c|c|c|c|}
\hline Phytochemical & Pulverized Sample & Methanol Extract & Hexane Extract \\
\hline Alkaloids & - & - & - \\
\hline Anthraquinones & + & + & + \\
\hline Carotenoids & - & + & + \\
\hline Flavonoids & + & + & - \\
\hline Phenols & + & + & + \\
\hline Saponins & + & + & + \\
\hline Steroids & + & + & + \\
\hline Tannins & + & + & + \\
\hline Terpenoids & + & + & + \\
\hline
\end{tabular}

Key: $(+)=$ presence of secondary metabolite; $(-)=$ absence of secondary metabolite.

\section{In vitro anti-inflammatory assay (egg albumen denatur-} ation method)

Denaturation of proteins is a well-documented cause of inflammation and rheumatoid arthritis. Several anti-inflammatory drugs have shown concentration-dose-dependent ability to inhibit thermally induced protein denaturation. The denaturation of albumin protein leads to formation of antigens which initiate type III hypersensitive reaction leading to inflammation [27]. The ability of plant extract to inhibit thermal denaturation of protein (egg albumin) is a reflection of its anti-inflammatory activity [28].
At the concentration of $200 \mu \mathrm{g} / \mathrm{mL}$, percentage inhibition of the standard, methanol and hexane extracts were 73.870, 47.176 and $20.500 \%$ respectively as shown in Table 2 . The anti-inflammatory activity shown by the extracts could be attributed to the presence of saponins, terpenoids and steroids in the methanol and hexane extracts of $F$. sur, which have been reported to exhibit anti-inflammatory activity [29]. The presence of polyphenols including tannins and flavonoids in $F$. sur have been reported to reduce inflammation and suppress several stages of angiogenesis, including endothelial cell migration, invasion, matrix metalloproteinase activity, and tube formation [30].

Table 2: Anti-inflammatory activity results for methanol and hexane extracts of $F$. sur.

\begin{tabular}{|c|c|c|}
\hline \multirow{2}{*}{ Concentration $(\mu \mathrm{g} / \mathrm{mL})$} & Methanol Extract & \% Inhibition (Mean \pm SD) \\
\cline { 2 - 3 } & $48.838 \pm 0.100^{*}$ & $48.215 \pm 0.018^{*}$ \\
\hline 1000 & $48.663 \pm 0.049^{*}$ & $41.250 \pm 0.047^{*}$ \\
\hline 800 & $47.330 \pm 0.007^{*}$ & $41.576 \pm 0.044^{*}$ \\
\hline 600 & $47.176 \pm 0.051^{*}$ & $20.500 \pm 0.028^{*}$ \\
\hline 200 & $36.692 \pm 0.032^{*}$ & $2.506 \pm 0.033^{*}$ \\
\hline 100 & & $73.870 \pm 0.002^{*}$ \\
\hline
\end{tabular}

Diclo: Diclofenac Sodium. Results were expressed as mean $(n=3) \pm$ standard deviation; The data were anaylsed using one-way ANOVA compared to diclofenac (reference drug). ${ }^{*} \mathrm{P}<0.001$.

\section{Antimicrobial assay}

\section{Agar well diffusion}

The antimicrobial activities of the extracts were determined at two concentration levels of 50 and $100 \mathrm{mg} / \mathrm{mL}$ for the agar well diffusion assay as shown in Table 3 . The agar well diffusion is carried out to test for the sensitivity of the organisms to the antimicrobial agent (plant extract). The diameter of the zone of inhibition determines the effectiveness of the extract against the microorganism. The larger the diameter, the greater the sensitivity of the microorganism to the extract. The sizes of the zone of inhibition are compared to standards to determine if the microorganism is sensitive or resistant to the plant extract. 


\section{Organic and Medicinal Chemistry International Journal}

Table 3: Mean zones of inhibition (ZI) for hexane and methanol extracts of $F$. sur and standard drugs ciprofloxacin and clotrimazole in agar well diffusion assay.

\begin{tabular}{|c|c|c|c|c|c|c|}
\hline \multirow{2}{*}{ Sample/Drug } & \multirow{2}{*}{ Conc. $(\mathbf{m g} / \mathbf{m L})$} & \multicolumn{5}{|c|}{ Zone of Inhibition (Mean \pm SD) (mm) } \\
\cline { 3 - 7 } & & C. albicans & S. aureus & P. aeruginosa & E. faecalis & E. coli \\
\hline Ciprofloxacin & 0.05 & NA & $37.4 \pm 0.26$ & $35.3 \pm 0.15$ & $27.0 \pm 0.15$ & $35.2 \pm 0.10$ \\
\hline Clotrimazole & 0.05 & $26.5 \pm 0.30$ & NA & NA & NA & NA \\
\hline \multirow{2}{*}{ Methanol } & 100.00 & $19.3 \pm 0.12$ & $22.0 \pm 0.09$ & $25.3 \pm 0.12$ & $25.0 \pm 0.09$ & $20.0 \pm 0.12$ \\
\cline { 2 - 7 } & 50.00 & - & $17.3 \pm 0.06$ & $19.0 \pm 0.09$ & $18.3 \pm 0.12$ & - \\
\hline \multirow{2}{*}{ Hexane } & 100.00 & $18.0 \pm 0.15$ & $20.0 \pm 0.12$ & $17.7 \pm 0.12$ & $17.0 \pm 0.09$ & $19.3 \pm 0.09$ \\
\cline { 2 - 7 } & 50.00 & - & $17.7 \pm 0.12$ & - & - & - \\
\hline
\end{tabular}

$\mathrm{NA}=$ Not Applicable, Diameter of cork borer $=10 \mathrm{~mm}$.

From the results obtained, the methanol and hexane extracts recorded zones of inhibition at the lower concentration of $50 \mathrm{mg} /$ $\mathrm{mL}$. At this concentration, the methanol extract recorded inhibition against E. faecalis, $S$. aureus and P. aeruginosa but showed no inhibition against $E$. coli and $C$. albicans. However, the hexane extract showed inhibition against only $S$. aureus at this concentration. At a concentration of $100 \mathrm{mg} / \mathrm{mL}$, all the tested organisms were susceptible to both the methanol and hexane extracts.

Generally, susceptibility increased with the increased concentration of extract as the zones of inhibition increased for all organisms. $P$. aeruginosa was the most susceptible to the methanol extract at $100 \mathrm{mg} / \mathrm{mL}$ with C. albicans being the least susceptible. At the same concentration, $S$. aureus was the most susceptible to the hexane extract with $E$. faecalis being the least susceptible. All the four tested bacteria were susceptible to the ciprofloxacin (standard drug) with the gram-positive bacteria $S$. aureus showing the highest susceptibility. Both extracts and clotrimazole (standard drug) showed activity against the fungus $C$. albicans.

\section{Broth microdilution}

The extracts showed broad spectrum antimicrobial activity against the tested organisms. The methanol extract showed a better antimicrobial activity (at MIC of $2.5 \mathrm{mg} / \mathrm{mL}$ to $10.00 \mathrm{mg} /$ $\mathrm{mL}$ ) against the test organisms than the hexane extract (at MIC of 20.00 to $40.00 \mathrm{mg} / \mathrm{mL}$ ). The results are shown in Table 4. The results from the antimicrobial assay performed showed that the two extracts of $F$. sur stem-bark exhibited varying inhibitory effects against the five selected microorganisms (two Gram-positive, two Gram-negative and one fungus). The best results were observed with the use of the methanol extract against all the selected microorganisms. The minimum inhibitory concentrations (MICs) were between the range of $2.5 \mathrm{mg} / \mathrm{mL}$ to $10.0 \mathrm{mg} / \mathrm{mL}$. The highest activity observed with the use of methanol extract was against P. aeruginosa with MIC of $2.5 \mathrm{mg} / \mathrm{mL}$. The antimicrobial activity shown by the extracts could be attributed to the presence of terpenoids, saponins and polyphenols such as flavonoids and tannins in the methanol and hexane extracts of $F$ sur which have been reported to exhibit antimicrobial activity [31,32].

Table 4: Minimum inhibitory concentrations (MIC) of extracts and reference drugs against test organisms.

\begin{tabular}{|c|c|c|c|c|}
\hline \multirow{2}{*}{ Test Organism } & \multicolumn{4}{|c|}{ Minimum Inhibitory Concentration $(\mathbf{m g} / \mathbf{m L})$} \\
\cline { 2 - 5 } & Methanol $(\mathbf{m g} / \mathbf{m L})$ & Hexane $(\mathbf{m g} / \mathbf{m L})$ & Ciprofloxacin $(\mathbf{m g} / \mathbf{m L})$ & Clotrimazole $(\mathbf{m g} / \mathbf{m L})$ \\
\hline C. albicans & 5.0 & 20.0 & NA & $1.25 \times 10^{-3}$ \\
\hline E. faecalis & 10.0 & 40.0 & $0.625 \times 10^{-3}$ & NA \\
\hline E. coli & 5.0 & 40.0 & $2.500 \times 10^{-3}$ & NA \\
\hline P. aeruginosa & 2.5 & 40.0 & $2.500 \times 10^{-3}$ & NA \\
\hline S. aureus & 5.0 & 40.0 & $0.625 \times 10^{-3}$ & NA \\
\hline NA=Not Applicable
\end{tabular}

NA=Not Applicable.

\section{In vitro antioxidant capacity}

The total antioxidant potential of a plant extract depends largely on both the constituent of the extract and the test system. Different factors can also influence the activity of the extract, therefore when carrying out a study related to the antioxidant and antiradical properties of plant products, more than one method is usually used to evaluate the antioxidant capacity/activity [33]. Considering the various mechanisms of antioxidant actions, the antioxidant properties of the extracts were evaluated by (DPPH) free radicals scavenging, Hydrogen Peroxide scavenging and the Total Antioxidant Capacity assays.

\section{DPPH radical scavenging capacity}

The DPPH radical scavenging activity of the extracts was used to determine and study the ability of the extracts of $F$. sur to mop up free radicals that may be found in animals and humans. Methanol and hexane extracts of $F$. sur and ascorbic acid (reference 
standard) scavenged DPPH radical in a dose dependent manner (Figure 1). The reference antioxidant (ascorbic acid), hexane and methanol extracts of $F$. sur showed antioxidant activity in the DPPH free radical scavenging assay with $\mathrm{IC}_{50}$ of ascorbic acid, hexane and methanol ranged from $3.17 \pm 0.32$ to $350.70 \pm 0.72$ $\mu \mathrm{g} / \mathrm{mL}$, as shown in Table 5.
Table 5: IC $\mathrm{C}_{50}$ of DPPH Radical Scavenging Activity for Hexane and Methanol extracts and Ascorbic Acid.

\begin{tabular}{|c|c|}
\hline Sample & $\mathbf{I C}_{\mathbf{5 0}}(\boldsymbol{\mu g} / \mathbf{m L})$ \\
\hline Ascorbic acid & $3.17 \pm 0.32$ \\
\hline Methanol & $89.95 \pm 0.30$ \\
\hline Hexane & $350.70 \pm 0.72$ \\
\hline
\end{tabular}

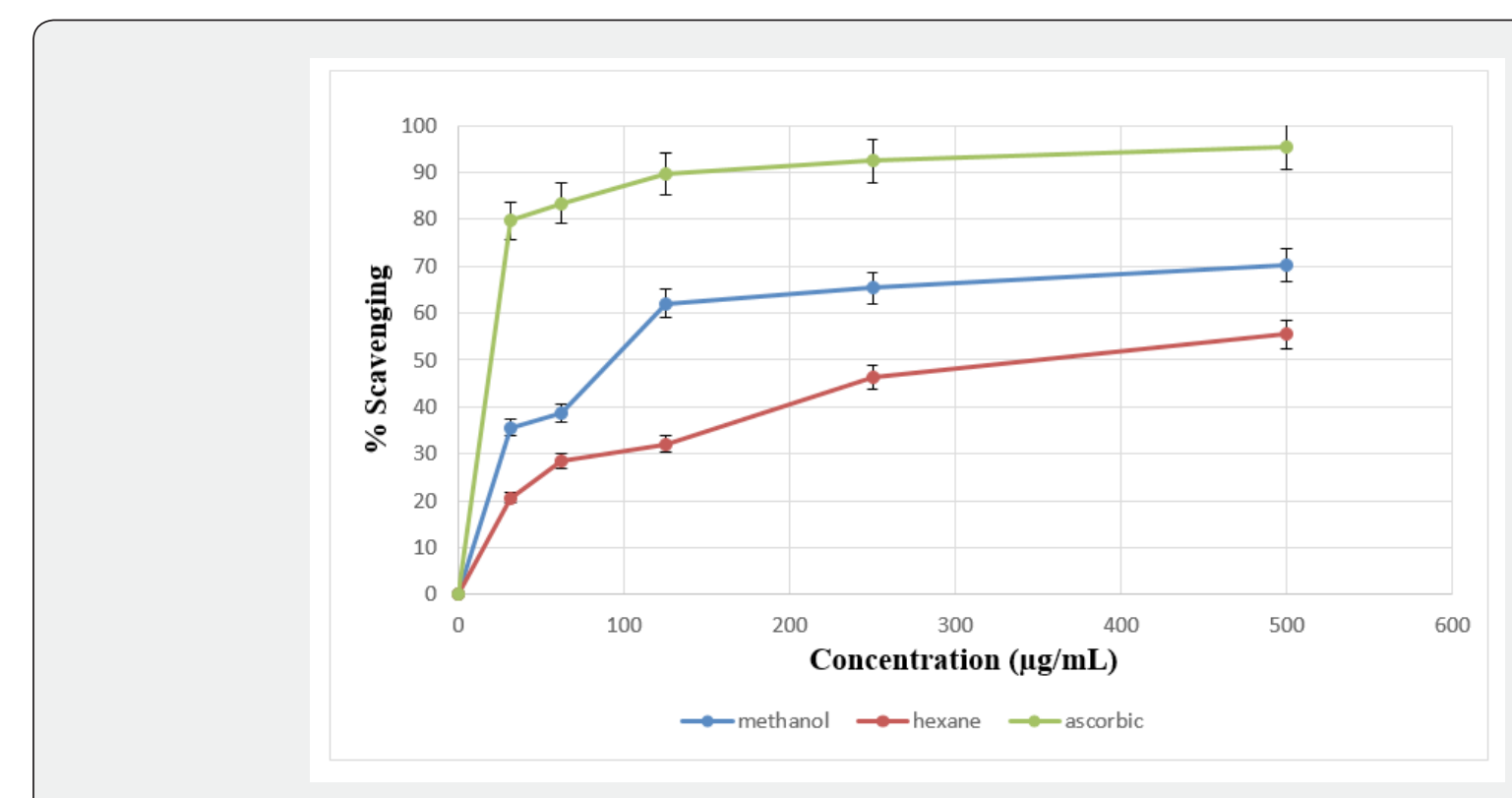

Figure 1: Comparative radical scavenging activity of the hexane and methanol extracts and ascorbic acid.

The results implied that the potency of the tested samples of extracts as antioxidants decreased in the order: ascorbic acid $>$ methanol > hexane (Figure 1). Methanol extract showed better antioxidant activity compared to the hexane probably due to the presence of the polyphenols that act as anti-aging agent by neutralizing the effect of free radicals [34]. Polyphenols including tannins and flavonoids have many favourable effects on human health, such as the inhibition of the low density proteins oxidiza- tion [35]. Though hexane and methanol extracts which comprise of a mixture of compounds were not as potent as the ascorbic acid, F. sur stem-bark extracts may be useful in the manufacture of drugs to help prevent or cure health problems that could arise from the systemic actions of oxidative agents, thus its usage in folk medicine for the treatment of sickle cell diseases in Burkina Faso [9].

\section{Hydrogen peroxide scavenging assay}

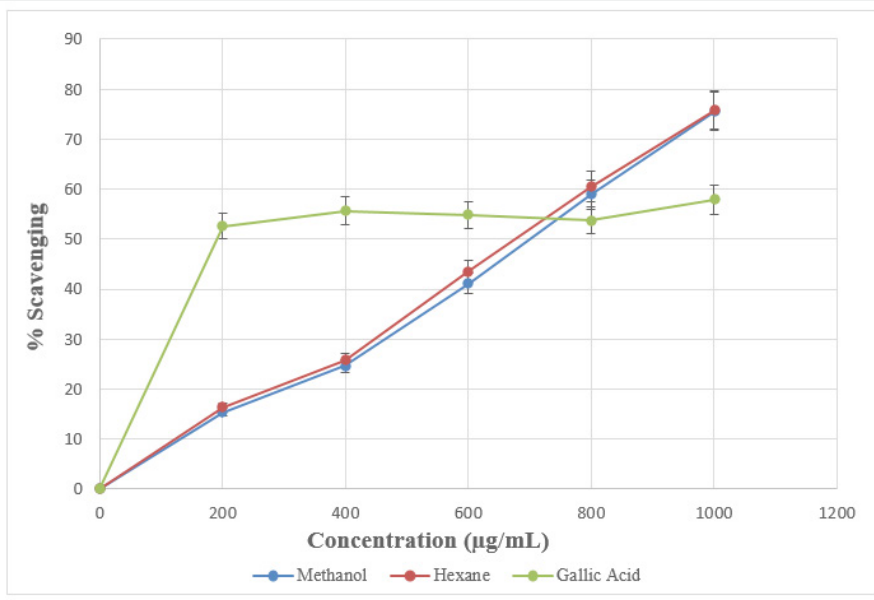

Figure 2: Comparative $\mathrm{H}_{2} \mathrm{O}_{2}$ radical scavenging activity of the hexane and methanol extracts and gallic acid. 
Non-radical oxidizing agents scavenging potential of the hexane and methanol extracts of $F$. sur were evaluated by the use of hydrogen peroxide $\left(\mathrm{H}_{2} \mathrm{O}_{2}\right)$ scavenging method. The results are shown in Table 6. Methanol and hexane extracts of $F$. sur and gallic acid (reference standard) exhibited $\mathrm{H}_{2} \mathrm{O}_{2}$ scavenging capacity in a dose dependent manner (Figure 2).

The $\mathrm{IC}_{50}$ of a sample is the concentration of the sample required to scavenge $50 \%$ of the peroxide in a system. It is used to evaluate the antioxidant capacity of a sample. The lower the $\mathrm{IC}_{50}$, the better the antioxidant potential of the sample under examination $[1,36]$. Results showed that, hexane and methanol extracts demonstrated a significant antioxidant activity in concentration-dose dependent manner. The $\mathrm{IC}_{50}$ values of gallic acid (standard drug), hexane and methanol extracts ranged from $204.40 \pm 0.01$ to $708.51 \pm 0.28$ $\mu \mathrm{g} / \mathrm{mL}$ as shown in Table 6.

Table 6: $I C_{50}$ of Hydrogen Peroxide Scavenging Activity.

\begin{tabular}{|c|c|}
\hline Sample & $\mathbf{I C}_{50}(\boldsymbol{\mu g} / \mathrm{mL})$ \\
\hline Standard (Gallic acid) & $204.40 \pm 0.01$ \\
\hline Hexane & $682.76 \pm 0.20$ \\
\hline Methanol & $708.51 \pm 0.28$ \\
\hline
\end{tabular}

From the results, both methanol and hexane extracts which comprise of a mixture of compounds showed slightly lower activity than gallic acid (reference standard), even though they are all good antioxidants. Bioactive isolates from these extracts responsible for antioxidant activity could be attributed to the terpenoids and polyphenols, such as tannins and flavanoids in F. sur and could be exploited for the treatment of oxidative-stress diseases [34].

\section{Total antioxidant capacity (TAC)}

Ascorbic acid also known as Vitamin C is an electron donor antioxidant and this property is responsible for all its known functions. Vitamin $\mathrm{C}$ is a potent reducing agent and scavenger of free radicals in biological systems. It is a cofactor for enzymes involved in regulating photosynthesis, hormone biosynthesis, and regenerating other antioxidants [37].

Concentrations of ascorbic acid ranging between 6.125 to 100 $\mu \mathrm{g} / \mathrm{mL}$ showed antioxidant activity and mean absorbances between $0.059 \pm 0.003$ to $0.932 \pm 0.002$ at wavelength of $695 \mathrm{~nm}$ (Figure 3). The TAC was found to be proportional to the concentration of extract. TAC of the extracts were examined by Phosphomolybdenum method and the results were expressed as gram ascorbic acid equivalent per 100 grams (gAAE/100g) [1]. The gAAE $/ 100 \mathrm{~g}$, represents the fraction of the plant extract that can act as ascorbic acid in $100 \mathrm{~g}$ of the extract. The hexane and methanol extracts had $17.863 \pm 0.037$ and $23.560 \pm 0.014$ gAAE $/ 100 \mathrm{~g}$, respectively, (Table 7).

Table 7: Total Antioxidant Capacity of Hexane and Methanol extracts expressed as gAAE/100g.

\begin{tabular}{|c|c|}
\hline Extract & TAC $($ gAAE $/ \mathbf{1 0 0 g})$ \\
\hline Hexane & $17.863 \pm 0.037$ \\
\hline Methanol & $23.560 \pm 0.014$ \\
\hline
\end{tabular}

TAC - Total Antioxidant Capacity; AAE - Ascorbic Acid Equivalent.

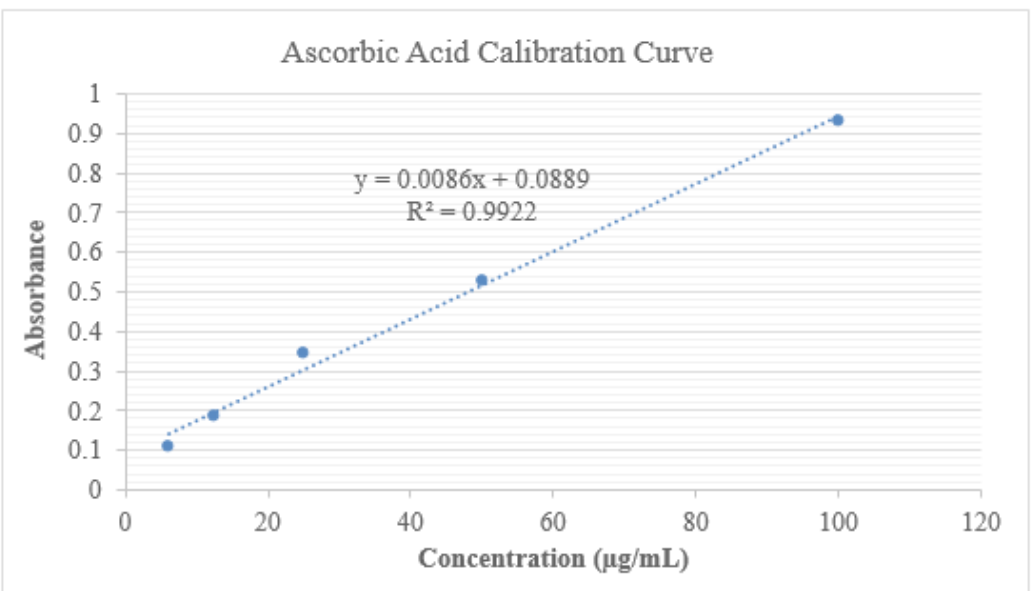

Figure 3: Absorbance of $\mathrm{PMo}_{4}^{\mathrm{V}} \mathrm{Mo}_{8}^{\mathrm{VI}} \mathrm{O}_{40}{ }^{7}$-(formed in ascorbic acid solution) against concentration of ascorbic acid solution.

Generally, the TAC increased with increasing concentration, thus the higher the TAC, the better the activity of the sample. Polyphenols including flavonoids are important natural antioxidants, which are basically associated with curing of various diseases and disorders including cancer, diabetes, gout, urolithiasis, obesity, and other diseases associated with ageing [38,39]. Both extracts demonstrated appreciable antioxidant activities due to the pres- ence of the various phytochemicals such as flavonoids, phenols, tannins, terpenoids among others in F. sur.

\section{Thin layer chromatography (TLC)}

The number of components present in the extracts were determined by the analytical TLC method. The chromatographic spots which were representative of compounds in the various extracts 
were observed and their Rf values determined. Table 8 gives the results of the TLC analysis. The hexane extract showed four spots and methanol five spots with $\mathrm{R}_{\mathrm{f}}$ values between 0.113 to 0.950 and 0.050 to 0.900 , respectively. The number of spots indicating the separated components in the two extracts were less for both extracts when compared to the phytoconstituents identified to be present in each stem-bark extract. This means that some of the components existed as isomers, did not elute due to the polarity of the mobile phase or co-eluted in mixtures and it may be necessary to employ two dimensional TLC, HPLC or column chromatography to achieve complete separation of the components [1].

Table 8: TLC results of extract showing various components and their retardation factor using hexane/ethyl acetate $(4: 1)$ as mobile phase.

\begin{tabular}{|c|c|c|}
\hline \multirow{2}{*}{ Components } & \multicolumn{2}{|c|}{ Retardation Factor, $\mathbf{R}_{\mathbf{f}}$} \\
\cline { 2 - 3 } & Hexane & Methanol \\
\hline A & 0.113 & 0.050 \\
\hline B & 0.250 & 0.250 \\
\hline C & 0.650 & 0.213 \\
\hline D & 0.950 & 0.263 \\
\hline E & - & 0.900 \\
\hline
\end{tabular}

\section{Conclusion}

The hexane and methanol extracts of $F$. sur showed the presence of varying secondary metabolites including saponins, tannins, terpenoids, steroids, flavonoids, phenols and anthraquinones. The study demonstrated that the hexane and methanol extracts of $F$. sur possess a variety of anti-inflammatory, antibacterial, antifungal and antioxidant activities. This implies the extracts could be effective against inflammations, infectious and diseases associated with oxidative-stress, and could become a potential therapeutic agent for their treatment. Further studies are ongoing in our laboratory towards isolation, characterization, identification and determination of biological activities present in the stem-barks of F. sur.

\section{Disclosure}

Part of this work was presented as a poster at the " 8 th Ghana Science Association, Research Seminar and Poster Presentations" held at the Kwame Nkrumah University of Science and Technology, Kumasi, Ghana, in May 2019.

\section{Conflicts of Interest}

The authors declare no competing financial, professional, or personal interests that might have influenced the performance or presentation of the work described in this manuscript. The authors declare that there is no conflict of interests regarding the publication of this paper.

\section{Acknowledgment}

The authors are grateful to the Departments of Chemistry and Pharmaceutical Microbiology as well as the Central
Laboratory of KNUST for the use of their facilities for this study. The authors appreciate Dr. Yaw Duah Boakye of the Department of Pharmaceutics, KNUST for helpful discussions. The authors are also grateful to Mr. Kennedy Ameyaw Baah, a PhD student of the Department of Chemistry for his assistance. We will also like to acknowledge Mr. Francis Amankwaah of the Department of Pharmaceutical Microbiology, Faculty of Pharmacy and Pharmaceutical Sciences, KNUST, for technical support.

\section{References}

1. Osei Akoto C, Acheampong A, Boakye YD, Akwata D, Okine M (2019) In vitro anthelminthic, antimicrobial and antioxidant activities and FTIR analysis of extracts of Alchornea cordifolia leaves. Journal of Pharmacognosy and Phytochemistry 8(4): 2432-2442.

2. Osei Akoto C, Acheampong A, Tagbor PD, Bortey K (2020) Determination of the antimicrobial and antioxidant activities of the leaf extracts of Griffonia simplicifolia. Journal of Pharmacognosy and Phytochemistry 9(2): 537-545.

3. Agyare CA, Boakye YD, Ayande GP, Titiloye N, Asiamah EA, et al. (2018) Assessment of wound healing properties of medicinal plants: The case of Phyllanthus muellerianus. Frontiers in pharmacology 9: 945.

4. Naidu DK, Radder BM, Patil PL, Hebsur NS, Alagundagi SC (2009) Effect of integrated nutrient management on nutrient uptake and residual fertility of chilli (Cv. byadgi dabbi) in a vertisol. Karnataka Journal of Agricultural Sciences 22(2): 306-309.

5. Wagstaff DJ (2008) International poisonous plants check list: an evidence based reference, CRC Press, New York 1-25: 235-271.

6. Louppe D, Oteng Amoako AA, Brink M (2008) Plant Resources of Tropical Africa. Timbers 1. PROTA foundation 7(1): 286.

7. Sanon S, Ollivier E, Azas N, Mahiou V, Gasquet M, et al. (2003) Ethnobotanical survey and in vitro antiplasmodial activity of plants used in traditional medicine in Burkina Faso. J Ethnopharmacol 86(23): $143-147$.

8. Grubben GJH (2008) Plant Resources of Tropical Africa (PROTA) (Vol 1) Prota.

9. Ramde Tiendrebeogo A, Tibiri A, Hilou A, Lompo M, Millogo Kone H, et al. (2012) Antioxidative and antibacterial activities of phenolic compounds from Ficus sur Forssk. and Ficus sycomorus L. (Moraceae): potential for sickle cell disease treatment in Burkina Faso. Int J Biol Chem Sci 6(1): 328-336.

10. Ishola IO, Olayemi SO, Yemitan OK, Ekpemandudiri NK (2013) Mechanisms of Anticonvulsant and Sedative Actions of the Ethanolic Stem-bark Extract of Ficus sur Forssk (Moraceae) in Rodents. Pakistan Journal of Biological Sciences 16: 1287-1294.

11. Olowokudejo JD, Kadiri, AB, Travih VA (2008) An ethnobotanical survey of herbal markets and medicinal plants in Lagos state of Nigeria. Ethnobotanical Leaflets 12: 851-865.

12. Fern K (2014) Plant Resources of Tropical Africa (PROTA). Useful Tropical Plants Database.

13. Solomon Wisdom GO, Shittu GA, Agboola YA (2011) Antimicrobial and Phytochemical Screening Activities of Ficus Sur (Forssk). New York Science Journal 4(1): 15-18.

14. Ogunlaja O0O, Moodley, R, Baijnath H, Jonnalagadda SB (2017) Nutritional evaluation, bioaccumulation and toxicological assessment of heavy metals in edible fruits of Ficus sur Forssk (Moraceae). Journal of Environmental Science and Health, Part B 52(2): 84-91.

15. Trease GE, Evans WC (2009) Pharmacognosy. (16 $6^{\text {th }}$ edn), W B Sanders Co Ltd, New York, pp. 1-604. 
16. Sree Kumari C, Yasmin N, Hussain MR, Babuselvam M (2015) In vitro anti-inflammatory and anti-arthritic property of Rhizopra mucronata leaves. Int J Pharma Sci Res 6: 482-485.

17. Wiegand I, Hilpert K, Hancock REW (2008) Agar and broth dilution methods to determine the minimal inhibitory concentration (MIC) of antimicrobial substances. Nat Protoc 3: 163-175.

18. Konning GH, Agyare C, Ennison B (2004) Antimicrobial activity of some medicinal plants from Ghana 75: 65-67.

19. Sánchez Moreno C, Larrauri JA Saura Calixto F (1998) A procedure to measure the antiradical efficiency of polyphenols. J Sci Food Agric 76: 270-276.

20. Mukhopadhyay D, Dasgupta P, Roy SD, Palchoudhuri S, Chatterjee I, et al. (2016) A Sensitive In vitro Spectrophotometric Hydrogen Peroxide Scavenging Assay using 1,10-Phenanthroline. Free Radicals Antioxidants 6: 124-132.

21. Prieto P, Pineda M, Aguilar M (1999) Spectrophotometric quantitation of antioxidant capacity through the formation of a Phosphomolybdenum Complex: Specific Application to the Determination of Vitamin E. Anal Biochem 269: 337-341.

22. Osei Akoto C, Rainier JD (2008) Harnessing glycal-epoxide rearrangements: The generation of the $\mathrm{AB}, \mathrm{EF}$, and IJ rings of adriatoxin. Angew Chemie Int Ed 47: 8055-8058.

23. Banu KS, Cathrine L (2015) General Techniques Involved in Phytochemical Analysis. International Journal of Advanced Research in Chemical Science (IJARCS) 2(4): 25-32.

24. Adebayo MA, Enitan SS, Owonikoko WM, Igogo E, Ajeigbe KO (2017) Haematinic Properties of Methanolic Stem Bark and Fruit Extracts of Ficus Sur in Rats Pre-exposed to Phenylhydrazineinduced Haemolytic Anaemia. Afr J Biomed Res 20: 85-92.

25. Nile SH, Khobragade CN (2009) Determination of nutritive value and mineral elements of some important medicinal plants from western part of India. J Med Plants 8: 79-88.

26. Podolak I, Galanty A, Sobolewska D (2010) Saponins as cytotoxic agents: a review. Phytochem Rev 9: 425-474.

27. Agrawal SS, Paridhavi M (2007) Herbal drug technology. ( $\left.2^{\text {nd }} e d n\right)$, University press Pvt. Ltd. Hyderabad.
28. Karthik K, Kumar PBR, Priya KRV, Kumar SK, Rathore RSB (2013) Evaluation of Anti-Intlammatory Activity of Canthium Parviflorum by in-vitro Method. Indian J Res Pharm Biotechnol 5674: 2320-2322.

29. Mohammed MS, Osman WJA, Garelnabi EAE, Osman Z, August J (2014) Secondary metabolites as anti-inflammatory agents. J Phytopharm 3: 275-285.

30. Taleb H, Morris RK, Withycombe CE, Maddocks SE, Kanekanian AD (2016) Date syrup derived polyphenols attenuate angiogenic responses and exhibits anti-inflammatory activity mediated by VEGF and COX-2 expression in endothelial cells. Nutr Res 36: 636-647.

31. Wallace RJ (2004) Antimicrobial properties of plant secondary metabolites. Proceedings of the Nutrition Society 63(4): 621-629.

32. Barbieri R, Coppo E, Marchese A, Daglia M, Sobarzo-Sánchez E, et al (2017) Phytochemicals for human disease: An update on plant-derived compounds antibacterial activity. Microbiological Research 196: 44-68.

33. Salazar R, Pozos ME, Cordero P, Perez J, Salinas MC, et al. (2008) Determination of the antioxidant activity of plants from Northeast Mexico. Pharmaceutical Biology 46(3): 166-170.

34. Bolann BJ, Ulvik RJ (1997) [How do antioxidants work?]. Tidsskrift for den Norske laegeforening: tidsskrift for praktisk medicin. ny raekke 117(13): 1928-1932.

35. Frankel EN, Waterhouse AL, Kinsella JE (1993) Inhibition of human LDL oxidation by resveratrol. Lancet 341(8852): 1103-1104.

36. Ibrahim T, Muluh K, Alexander A (2016) Phytochemical Screening, Antioxidant and Antibacterial Activities of Commiphora kerstingii. Int Biol Biomed J2: 127-133.

37. Pehlivan FE (2017) Vitamin C: An Antioxidant Agent. In tech Open.

38. SH Nile, SW Park (2015) Chromatographic analysis, antioxidant, antiinflammatory, and xanthine oxidase inhibitory activities of ginger extracts and its reference compounds. Ind Crops Prod 70: 238.

39. Shoaib M, Ghias M, Shah SWA, Ali N, Umar MN, et al. (2019) Synthetic flavonols and flavones: A future perspective as anticancer agents. Pak J Pharm Sci 32(3): 1081-1089.

\begin{tabular}{l} 
Your next submission with Juniper Publishers \\
will reach you the below assets \\
- Quality Editorial service \\
- Swift Peer Review \\
- Reprints availability \\
- E-prints Service \\
- Manuscript Podcast for convenient understanding \\
- Global attai nment for your research \\
- Manuscript accessibility in different formats \\
( Pdf, E-pub, Full Text, Audio) \\
- Unceasing customer service \\
Track the below URL for one-step submission \\
https://juniperpublishers.com/online-submission.php \\
\hline
\end{tabular}

